\title{
Dominance induction of fruitlet shedding in Malus $\times$ domestica (L. Borkh): molecular changes associated with polar auxin transport Valeriano Dal Cin ${ }^{* 1,3}$, Riccardo Velasco ${ }^{2}$ and Angelo Ramina ${ }^{1}$
}

\author{
Address: ${ }^{1}$ Department of Environmental Agronomy and Crop Science, University of Padova, Viale dell'Università 16, 35020 Legnaro (Padova), \\ Italy, ${ }^{2}$ Experimental Institute for Agriculture, via Mach 2 San Michele all'Adige, 38010 Trento, Italy and ${ }^{3}$ Horticultural Sciences, University of \\ Florida, Gainesville, PO Box 116090, USA \\ Email: Valeriano Dal Cin* - vdalcin@ufl.edu; Riccardo Velasco - riccardo.velasco@iasma.it; Angelo Ramina - angelo.ramina@unipd.it \\ * Corresponding author
}

Published: 26 November 2009

BMC Plant Biology 2009, 9:139 doi:10.1 186/147/-2229-9-139
Received: 17 June 2009

Accepted: 26 November 2009

This article is available from: http://www.biomedcentral.com/I47I-2229/9//39

(c) 2009 Dal Cin et al; licensee BioMed Central Ltd.

This is an Open Access article distributed under the terms of the Creative Commons Attribution License (http://creativecommons.org/licenses/by/2.0), which permits unrestricted use, distribution, and reproduction in any medium, provided the original work is properly cited.

\begin{abstract}
Background: Apple fruitlet abscission is induced by dominance, a process in which hormones such as auxin, cytokinins and strigolactone play a pivotal role. The response to these hormones is controlled by transcription regulators such as Aux/IAA and ARR, whereas auxin transport is controlled by influx and efflux carriers.

Results: Seven partial clones encoding auxin efflux carriers (MdPINI_A, MdPINI_B, MdPINIO_A, MdPINIO_B, MdPIN4, MdPIN7_A and MdPIN7_B), three encoding auxin influx carriers (MdLAXI, MdLAX2 and MdLAX3) and three encoding type A ARR cytokinin response regulators (MdARR3, MdARR4 and MAARR6) were isolated by the use of degenerate primers. The organization of the PIN multigene family in apple is closer to Medicago truncatula than to Arabidopsis thaliana. The genes are differentially expressed in diverse plant organs and at different developmental stages. MdPINI and MdPIN7 are largely more expressed than MdPINIO and MdPIN4. During abscission, the transcription of these genes increased in the cortex whereas in the seed a sharp fall was observed. The expression of these genes was found to be at least partially controlled by ethylene and auxin.

Conclusion: The ethylene burst preceding abscission of fruitlets may be responsible for the decrease in transcript level of MDPINI, MDARR5 and MDIAA3 in seed. This situation modulates the status of the fruitlet and its fate by hampering the PAT from the seeds down through the abscission zone $(A Z)$ and this brings about the shedding of the fruitlet.
\end{abstract}

\section{Background}

Abscission is a coordinated process tightly regulated by the interplay of several factors, among which auxin and ethylene play a pivotal role $[1,2]$. Leaf deblading and ethylene application lead to premature abscission of the organ due to the disruption of the auxin flux and activation of the abscission zone (AZ) at the base of the petiole $[3,4]$.
In the commonly accepted model, as demonstrated in the Arabidopsis etr1-1, ethylene coordinates abscission. In this mutant, flower abscission is significantly delayed because the ethylene receptor (ETR1) is hampered in ethylene binding activity, leading to partial ethylene insensitivity. Although ethylene accelerates abscission, it is strictly not necessary for shedding, indicating that a very complex interplay of events control the process [5-7]. 
Indeed, it has been shown that ethylene-dependent and independent pathways converge in determining flower abscission [8].

It has also been postulated that prevention of abscission requires a continuous and constant auxin transport through the AZ [1]. Besides preventing abscission, auxin regulates a tremendous number of processes, for instance root meristem activity, organogenesis, and vascular tissue differentiation [9-11]. Only recently the outstanding complex mode of action of auxin has been partially unraveled [12]. The most common auxin in plant, indol-3-acetic acid (IAA), binds and is perceived by TIR1, an F-box protein [13]. TIR1 interacts in the SCF complex to bring about the degradation of Aux/IAA transcriptional regulators [14]. These proteins are active repressors of auxin responsive genes and are encoded by a large multigene family [15]. Auxin applications enhance the transcript amount of most of the Aux/IAAs in several species [16-19]. Another enthralling field concerns auxin transport [20], which can be classified as either polar (PAT) or non polar. However, the PAT is acquiring ever-growing interest and may be the most important means of auxin relocation [21]. IAA is taken up into the cell by a combination of lipophilic diffusion, symport via AUX and LAX (LIKE-AUX1) permeases, and ATP-dependent transport by a P-glycoprotein [22-25]. Auxin export is mediated by PIN-FORMED (PIN) facilitators and by ATP activated PGPs (Phosphoglycoproteins) [26-30]. PINs and PGPs were shown to characterize coordinated and independent auxin transport mechanisms, and function interactively in a tissue-specific manner [31]. Nevertheless, the function of the PGPs is nonspecific and mainly applies to auxin excess [32]. As a matter of fact, it is the asymmetric cellular localization of PIN proteins that determines the direction of the auxin flow [20]. Although different PINs are implicated in specific developmental processes, there seems to be redundancy as indicated by the ectopic expression of PIN proteins in some mutant combinations $[20,33,34]$.

The modes of action of auxin and ethylene elucidated in A. thaliana have been extended to other model species such as tomato [35,36]. Yet, little is known about the interactions between these two hormones during abscission induction of organs other than debladed leaves or senescing flowers. In particular, the apple cluster during the immature fruit drop represents an ideal system to study the shedding of actively growing organs [37]. At this developmental stage, the shedding process involves almost exclusively lateral fruitlets in which abscission is preceded by an increase in ethylene biosynthesis and sensitivity [38-40]. According to the correlative basis reknown model the central fruitlet exerts a dominant effect over lateral fruitlets because it is at a more advanced stage of development $[37,41]$. As assessed by the canalization theory the strong auxin flow coming from the central fruitlet, down to the peduncle through the $\mathrm{AZ}$ into the twig, depolarizes the weak auxin flows from the lateral fruitlets causing their abscission [42].

Apical dominance is a complex physiological process largely controlled by auxin and its interaction with two additional hormones: cytokinins and MAX (more axillary branching [43-45]. Cytokinins produced in the roots are directed to organs (shoot apical meristems, fruits, etc) whose sink strength is related to their ability in producing and exporting auxin [46]. This process directs more cytokinins which stimulate growth $[47,48]$. In the case of apical dominance of shoot meristems, lateral bud outgrowth occurs when the auxin flow from the apex is hampered, dominance is weakened, and cytokinins are redirected to axillary meristems $[43,44]$. Besides the main cytokinin stream coming from the roots, the hormone can also be produced in other tissues. For instance, following decapitation, a prompt increase in transcripts for the key enzyme in cytokinin biosynthesis, adenosine phosphate-isopentenyltransferase, occurs in the stem xylem [49]. The cytokinins produced here may then be translocated into the axillary meristems where they stimulate the lateral bud outgrowth. The cytokinin signaling relies on a two-component signal transduction system and upon activation it determines changes in transcript level of genes encoding proteins, such as the same cytokinin response regulators (ARRs type A) which are involved in various processes $[50,51]$.

The second hormone which interacts with auxin is MAX, a carotenoid derived compound which has been only recently characterized as strigolactone, but its existence had been proven before by the discovery of the pea rms, petunia dad and A. thaliana max mutants [52-55]. These plants display excessive branching, indicating that strigolactone is a positive regulator of apical dominance. Among the several genes related to this hormone, AtMAX2 encodes an F-box protein [55]. Although the F-box protein is not required for the synthesis of MAX it is involved in the transduction of the signal at the level of the node $[56,57]$.

The isolation, characterization and expression of some genes encoding elements involved in auxin transport, as well as of type A MAARRs and MAMAX2, were pursued to elucidate at the molecular level the interactions among ethylene, PAT and cytokinin in relation to the immature apple fruit abscission,

\section{Results \\ Identification of elements involved in PAT in MalusXdomestica}

During a differential display study between abscising and not abscising fruitlet populations, several clones related to auxin were isolated. However, only two transporters were 
found: with one encoding an auxin hydrogen symporter whereas the other one was too short and located in a highly conserved region which made further studies complicated [58]. We then pursued the isolation of other elements involved in auxin transport by the amplification of fruitlet cDNAs with degenerate primers and the following 3 ' race. This approach allowed the identification of seven PIN (Additional file 1) and three LAX (Additional file 2) partial clones. The name was chosen according to the highest level of similarity with the PIN of A. thaliana and $M$. truncatula, two dicotyledonous species whose members have all been well characterized at the genomic level. MdPIN1_A (EF406255) MdPIN1_B (EF406256), MdPIN10_A (EF406260), and MdPIN10_B (EF406261) are likely to be orthologous to AtPIN1, whereas MdPIN7_A (EF406258), MdPIN7_B (EF406259), and MdPIN4 (EF406257) may be orthologous to AtPIN3, AtPIN4 or AtPIN7 (Figure 1 and Additional file 3). Nevertheless, this association has to be definitely proven by functional and synteny studies. The isolation of different alleles (presented here with a letter) and the fact that MdPIN1 and MdPIN10 are different genes and not allelic forms was ascertained by the isolation and comparison of the genomic clones (MdPIN1: EF406268; MdPIN10_A: EF406269; MdPIN10_B: EF406270). The amplification of the genomic clones allowed the identification of the third, fourth and fifth intron as indicated in the work by [59]. The comparison of these regions indicated that the third intron was identical among the three clones whereas the fourth one was identical only between MdPIN10_A and MdPIN10_B. The fifth intron was the most divergent, but the identity between the two alleles of MdPIN10 was still 97.1\% (Additional file 4). Concerning the LAX genes, MdLAX1 (EF406263) may be orthologous to AtAUX1, whereas MdLAX2 (EF406264) and MdLAX3 (EF406262) are more divergent and closer to AtLAX (Figure 2 and Additional file 5).

Since fruitlets are actively growing organs and auxins install apical dominance by directing the cytokinin stream derived from the root, some elements involved in cytokinin signal transduction were also isolated. These clones showed a high level of similarity to type A response regulators (ARRs, A. thaliana Response Regulators) of several species (results not shown) and were named according to the most closely related AtARR: MdARR6 (EF406267), MdARR3 (EF406265) and MdARR4 (EF406266).

\section{Expression analysis in the different tissues}

The RT- PCR expression analysis performed with ${ }^{33} \mathrm{P}$ labeled degenerate primers visualized the relative level of expression among the different PIN genes. The high intensity of the band of MdPIN1 and MdPIN7 indicates that the transcripts of these genes are largely predominant on MdPIN10 and MdPIN4 (Additional file 6). This result was

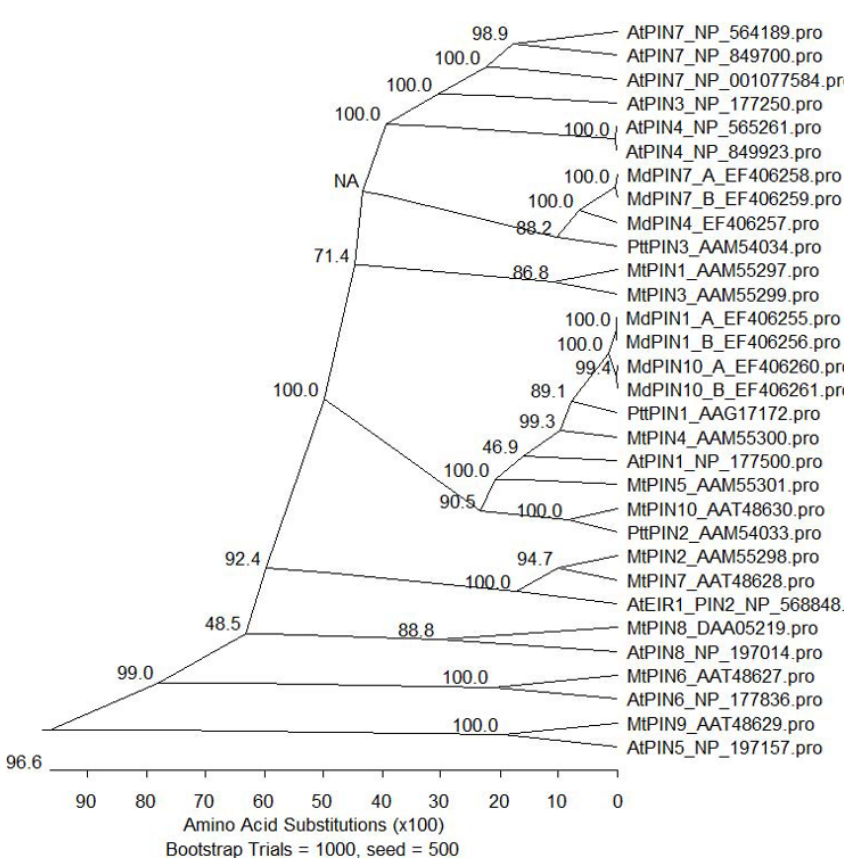

Figure I

PIN Phylogenetic tree. Phylogenetic study of the PIN isolated in this study (Malus $\times$ domestica (Md)) with those of Arabidopsis thaliana (At), Medicago truncatula (Mt), and Populus tremula $\times$ Populus tremuloides (Ptt). (MdPINI_A, EF406255; MdPINI_B, EF406256; MdPIN4, EF406257; MdPIN7_A, EF406258; MdPIN7_B, EF406259; MdPINIO_A, EF406260; MdPINIO_B, EF40626I; AtPINI, NP_I77500; AF089085; AtPIN2, NP_568848; AtPIN3, NP_177250; AtPIN4, NP_56526I, NP_849923; AtPIN5, NP_197I 157; AtPIN6, NP_177836; AtPIN7, NP_564I89, NP_849700, NP_00 I077584; AtPIN8, NP_1 970 I4; MtPINI, AAM55297; MtPIN2, AAM55298; MtPIN3̄, AAM55299; MtPIN4,

AAM55300; MtPIN5, AAM5530I; MtPIN6, AAT48627; MtPIN7, AAT48628; MtPIN8, DAA05219; MtPIN9, AAT48629; MtPINI 0, AAT48630; PttPINI, AAGI7I72; PttPIN2, AAM54033; PttPIN3, AAM54034). Bootstrap values are reported.

also confirmed by the number of cycles used in the RTPCR: on average, MdPIN1 expression was studied at 33 cycles, MdPIN7 at 32 cycles, MdPIN10 at 35 cycles and MdPIN4 at 37 cycles (Table 1). Results showed a differential expression of the orthologs (Figure 3). MdLAX1 transcripts accumulated in all the tissues, although the signal was barely detectable in fruit seed and senescing leaf. MdLAX2 and MdLAX3 transcripts showed a similar pattern: in the seedlings the transcripts accumulated mainly in root and hypocotyl, whereas in fruit mainly in cortex. The transcripts were also abundant in the flower. Transcripts decreased during leaf ageing (from shoot to senescing leaf). Transcripts were also detected in shoot, whereas in fruitlet, the highest amount was observed in peduncle. MdPIN1 transcripts displayed a similar pattern to 


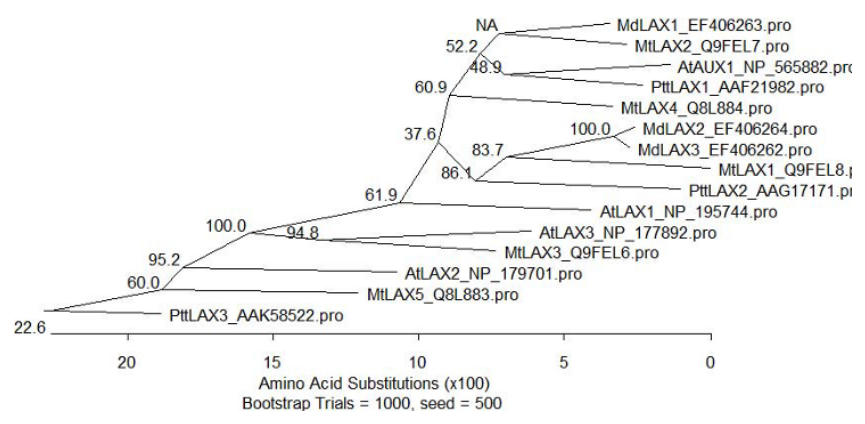

Figure 2

AUX Phylogenetic tree. Phylogenetic study of the AUX and AUX-Like isolated in this study (Malus $\times$ domestica (Md)) with those of Arabidopsis thaliana (At), Medicago truncatula $(\mathrm{Mt})$, and Populus tremula $\times$ Populus tremuloides $(\mathrm{Ptt})$. (MdLAXI, EF406263; MdLAX2, EF406264; MdLAX3, EF406262; AtAUXI, NP 565882; AtLAXI, NP 195744, NP 9747I 9; AtLAX2, NP 17970I; AtLAX3, NP I77892; MtLAXI, Q9FEL8; MtLAX2, Q9FEL7; MtLAX3, Q9FEL6; MtLAX4, Q8L884; MtLAX5, Q8L883; PttLAXI, AAF2 1982; PttLAX2, AAG 17I7I; PttLAX3, AAK58522). Bootstrap values are reported.

MdLAX1, with the signal slightly decreasing during flower and leaf senescence. MdPIN10 transcripts were mainly detected in seedlings grown in dark, above all in hypocotyl and peduncle; the transcripts slightly decreased along senescence of both flower and leaf. MdPIN4 displayed a pattern similar to MdPIN10, except in the flower where the signal was strong and apparently not affected by ageing. MdPIN7 transcripts were detected in all organs, with a slight increase in the seedlings grown in dark compared to those grown in light, and during flower senescence, whereas a decrease was observed in senescing leaf. MdIAA3 transcripts were present in all tissues at similar level, whereas MdIAA7 transcripts displayed a decrease during both flower and leaf senescence, and a weaker signal in seed than in peduncles and cortex. The strongest MdMAX2 signal was observed in cotyledons of light grown seedlings and in seeds of ripe and immature fruits. Furthermore, the transcripts accumulated preferentially in shoots rather than in fully expanded and senescing leaves. Besides fruit cortex and leaf, MdARR6 transcript accumulation pattern was the opposite to that of MdMAX2, with the signal decreasing in senescing flower and leaf. The MdARR3 signal, although weak in all tissues, was mainly detected in the root of light grown seedlings. In the other tissues, transcripts mainly accumulated in leaf. MdARR4 transcripts accumulated preferentially in dark grown seedling and, opposite to MdARR3, transcript amount decreased along leaf ageing.

\section{Expression analysis during abscission induction}

MdPIN1 transcript amount displayed a dramatic decrease in seeds whereas not much difference was observed in the other tissues (Figure 4). MdPIN10 transcripts increased in cortex by day 7 with a concurrent slight decrease in peduncle, whereas in AZ the decrease started already at day 5 . MdPIN4 transcripts increased throughout the experiment in cortex, whereas in peduncle the increase was moderate and started later, concurrently with a decrease in AZ. MdPIN7 expression showed only a late increase in cortex. MdLAX1 transcripts slightly declined in seeds and increased in both cortex and peduncles. In AZ a transient decrease was observed at day 5. Since MdLAX2 and MdLAX3 showed the same pattern of expression, only results related to MdLAX2 are presented in Figure 2. Besides a slight transient decrease at day 3 in peduncle and a late surge in cortex, transcript levels remained unchanged along the experiment. MdIAA3 transcripts decreased by day 7 in seeds and increased by day 5 and 7 in peduncles and cortex, respectively. MdIAA7 transcript amount significantly increased in cortex at day 7 along with a dramatic decrease in peduncles. MdARR6 mRNA amount steadily increased in cortex, whereas in seeds and peduncles a decrease was observed at day 7. Analogously, MdARR3 transcripts increased in cortex and decreased in seeds and slightly in peduncles. Concerning MdARR4, mRNA amount already increased in cortex at day 3 , then remained constant. MdMAX2 transcripts decreased late in seeds and increased at day 3 in cortex. The up-regulation was maintained in the following dates: in peduncle a transient decreased at day 3 and 5 was observed whereas in AZ mRNA gradually declined along the experiment.

\section{Peduncle development}

Peduncle growth was monitored along abscission up to 14 days after BA application (Figure 5). The length of the NAF peduncles was significantly shorter than the AF along the whole experiment. The initial length of the peduncles, according to the value of the intercepts calculated by a linear regression, was $2.63 \mathrm{~cm}$ and $3.04 \mathrm{~cm}$ for NAF and AF, respectively. On the other hand, according to the line equations (a regression value of 0.92 in NAF and 0.99 in $\mathrm{AF})$, the growth rate of the fruitlet peduncle was similar with values of 0.027 and 0.034 , respectively. Concerning diameter, the NAF was characterized by a thicker peduncle $(0.15 \mathrm{~cm})$ than the AF $(0.12 \mathrm{~cm})$, but no relevant changes were observed along the experiment.

\section{Auxin effect on PIN transcripts}

Auxin application determined a dose-dependent response in PIN transcripts. Nevertheless, there was a clear increase only in MdPIN4 and MdPIN10, whereas in the case of MdPIN1 and MdPIN7 auxin application seemed only to counteract the natural decrease in transcripts as observed in the mock control (Additional file 7).

\section{Ethylene effect on transcript accumulation}

Fruitlet clusters were flushed with propylene or treated with 1-MCP for 24 hours and expression analysis was carried out in peduncles (Figure 6). Compared to the control, 
Table I: List of primers utilized in the expression analysis

\begin{tabular}{|c|c|c|c|c|c|}
\hline Gene & Tm & $\mathbf{N}^{\circ}$ cycles & Primer forward & Primer reverse & Accession number \\
\hline MdLAXI & 57 & 31 & 5'-AGTGCTATCAGTGCAAGC-3' & 5'-CCGGAGAATTTTTCTGACTG-3' & EF406263 \\
\hline MdLAX2 & 57 & 31 & 5'-CTACCACCACCACATCAC-3' & 5'-GGAAACACCACCAATTCAC-3' & EF406264 \\
\hline MdLAX3 & 57 & 31 & 5'-САTCACTAAGCTTCTCTCTC-3' & 5'-CAАCACCAATCCACТСТTC-3' & EF406262 \\
\hline MdPINI & 71 & 33 & 5'-ATTTTACCACGGCGGGCAAGG-3' & 5'-CCTTCCCGCCATTGTTGTCCT-3' & EF406255/EF406256 \\
\hline MdPINIO & 71 & 35 & 5'-CGGCGGACAGAATAATGCAGT-3' & 5'-GAAGATCCTTCCCGCCATTGG-3' & EF406260/EF40626I \\
\hline MdPIN4 & 71 & 37 & 5'-ACAATTCAACAGCAGCAGCA-3' & 5'-CGGTCCCACCAAAAACATGG-3' & EF406257 \\
\hline MdPIN7 & 71 & 32 & 5'-TTTGGGTTTTATCCCGCGCAGA-3' & 5'-CGGCGGCTGCCTGATTTTTTGC-3' & EF406258/EF406259 \\
\hline MdIAA3 & 62 & 29 & 5'-GGTTGAGAATCATGAAGGGT-3' & 5'-AAAGCCCGAGCTCTATGTCT-3' & DQ848594 \\
\hline MdIAA7 & 64 & 30 & 5'-AATGCAAGAACAGGAGCTGA-3' & 5'-TCCAATCAGTCGAACAACCT-3' & DQ848598 \\
\hline MdAHS & 58 & 30 & 5'-CTTCGTTGGGTCAATTACG-3' & 5'-GGCAATAATCACTCCAAGG-3' & EF406254 \\
\hline MdMAX2 & 61 & 30 & 5'-ACATTGCGGAAGCTCTTC-3' & 5'-GCATCTTCGAATCGACAAC-3' & DY2420I5 \\
\hline MdARR6 & 61 & 30 & 5'-GCATCATCATCTCCСТCСТCT-3' & 5'-CAATCCATCGTGTGCAATCTC-3' & EF406267 \\
\hline$M d A R R 3 / 4$ & 61 & 30 & 5'-TGATCCGACGATTGCTCCATC-3' & 5'-CAGCGTTGGTCATTTTCAACC-3' & EF406265/EF406266 \\
\hline MdUBI & 61 & 28 & 5-CATCCCCCCAGACCAGCAGA-3 & 5-ACCACGGAGACGCAACACCAA-3 & DQ438989 \\
\hline$r 18 S$ & 62 & 25 & 5-GTTACTTTTAGGACTCCGCC-3 & 5-TTCCTTTAAGTTTCAGCCTTG-3 & \\
\hline
\end{tabular}

Specific primers utilized for the expression analysis. Tm indicates the annealing temperature used in the PCR reaction. The number $\left(\mathrm{N}^{\circ}\right)$ of cycles is that utilized in the experiments reported. The accession number is also reported in the right column.

MdLAX1, MdLAX2, MdPIN1, MdPIN10, MdARR6 and MdARR3 transcript amount was decreased by propylene and increased by 1-MCP, especially in the case of MdPIN1. As far as MdPIN4, MdPIN7 and MdMAX2 are concerned, the transcripts accumulated throughout the experiment in an ethylene-independent manner, whereas no chemical effect was observed on MdARR4 transcripts.

\section{Discussion}

\section{Which are the orthologs?}

The isolation of various PIN and LAX clones in Malus $\times$ domestica indicates the presence of multigene families. Because of the identical expression profile and the high identity values, MdLAX2 and MdLAX3 are likely to be alleles. On the contrary, the alignment of the PINs presented here with the PINs of A. thaliana and M. truncatula, the isolation of the two genomic alleles of MdPIN10 and the differences at the level of the introns, and expression pattern of MdPIN1 and MdPIN10 indicate that they may be paral- ogous, as it has been reported for MtPIN4 and MtPIN5 [59]. The same organization was found in Vitis vinifera, Populus trichocarpa and Oryza sativa. Interestingly, A. thaliana presents a transcript variation of the PIN1 gene (Additional file 8). Another interesting point is that MdPIN7 and MdPIN4 are closely related to each other as found for MtPIN1 and MtPIN3, whereas in A. thaliana, besides AtPIN3 and AtPIN7 (showing a high level of similarity) a third member, AtPIN4, is present in the same cluster. The overall data indicate a different organization of the PIN members in the species discussed here. Similar organization for this cluster was found in Populus and vitis but not in Oryza (Additional file 8). This may be due to duplication and specialization of the members along plant speciation after $P$. patens. The organization of the auxin influx carriers was not completely conserved either (Additional file 9) This observation also highlights the difficulty in identifying the physiological orthologs of Arabidopsis genes. 


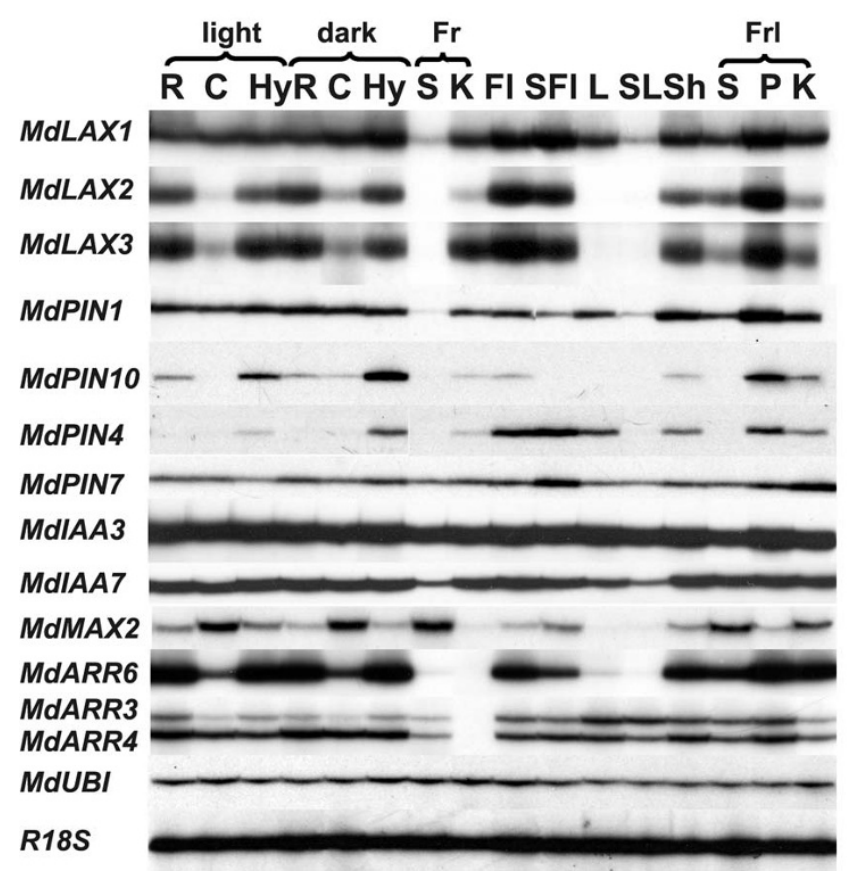

Figure 3

Expression study in different organs of MalusXdomestica. Description: Expression analysis in different tissues and at different developmental stages performed by RT-PCR.

Root $(R)$, cotyledon $(C)$ and hypocotyl $(\mathrm{Hy})$ were collected from seedlings after 4 days of de-etiolation or left in the dark. Seed (S) and cortex (K) excised from fruit (Fr) at commercial harvest. Flowers (FI) collected at full bloom and senescing un-pollinated flowers (SFI) were those not pollinated. Leaves were divided in mature fully expanded leaf $(L)$, senescing leaf (SL) and shoot (leaflet and stem) (Sh). Fruitlets (Frl) were collected at 7 days APF and seed (S), peduncle $(\mathrm{P})$ and cortex (K) dissected.

The expression of the PAT elements is driven by external and internal cues

During germination when a young plant has to grow through the soil particles and reach the surface, the cotyledons remain upright and the hypocotyl keeps on elongating until it reaches the light. The difference between hypocotyl length of seedlings grown in dark and seedlings during de-etiolation was also observed in our experiment (data not shown). Expression analysis performed on the seedlings indicated that light mainly affects transcript amount of the auxin efflux carriers (MdPIN10 and MdPIN4) in hypocotyl as reported in pea, whereas the influx carrier transcript quantity was barely changed (MdLAX1) [60]. According to the results, light negatively regulates PIN expression during germination. Considering the expression domains of the Arabidopsis PINs at this stage the expression level at different developmental stages and in different organs, and the sequence similarity to known proteins and genes, MdPIN1 and MdPIN10 analogously to AtPIN1, would be involved in PAT directed to the root apical meristems[31]. On the other hand, MdPIN4 and MdPIN7, similarly to AtPIN3 and AtPIN7, may have an important role in hypocotyl elongation because they are expressed in hypocotyl epidermis and bundle sheath. However, immunolocalization and GFP studies are necessary to further investigate which elements in apple are the physiological orthologs to those of Arabidopsis.

Moreover, a general decrease in the transcript amount of MdLAX1, MdLAX2, MdLAX3, MdPIN1 and MdPIN10 was observed during senescence and ageing of different organs/tissues such as seed, leaf, flower and cortex. As discussed above, it is well known that a drop in auxin level occurs during leaf senescence preceding abscission. It has also been extensively demonstrated that the majority of Aux/IAA transcripts increase after auxin application in several systems, making them good molecular markers for the auxin endogenous level [18,27,61-63]. Furthermore, analogously to the PIN clones herein isolated, transcripts of some PINs were found to increase following auxin application in poplar, pea and $A$. thaliana $[60,64,65]$. Therefore, it is conceivable that the change in MdIAA7 and PIN transcripts occurring at certain developmental stages is at least partially auxin-related. On the other hand, the clone MdIAA3 may represent a gene that is highly expressed and only partially controlled by auxin. In addition, a slight increase in MdLAX1, MdPIN4 and MdPIN7 transcripts was monitored in senescing flowers, as reported during daffodil flower senescence [66]. These results indicate that the expression of the PAT elements, besides being under auxin control, is developmentally and tissue specifically regulated, as previously reported for hybrid aspen and $A$. thaliana, respectively $[64,65]$.

\section{PAT transcripts are differentially regulated during abscission induction}

The expression analysis performed along abscission induction pointed out a general increase in the transcription of PAT elements in cortex, whereas a predominant decrease was observed in seeds. Furthermore, considering that MdPIN1 and MdPIN7 are the most abundant transcripts (Figure 3, Figure 4, and Table 1) and that MdPIN10 and MdPIN4 were not detected in seed, it appears that during the fruitlet abscission a decrease in PAT at the level of the seed occurs. On the other hand, the low growth rate [61] and the high level of PAT transcripts, such as MdIAA3 and MdIAA7 (this work) observed in the cortex of AF, indicate a delay in development. This hypothesis is strengthened by the up-regulation of MdARR6, MdARR3 and MdARR4 occurring in the cortex of AF. In fact, the type A ARR is the best indicator of the level of the cytokinin (the hormone that stimulates cell division [67]), in which 

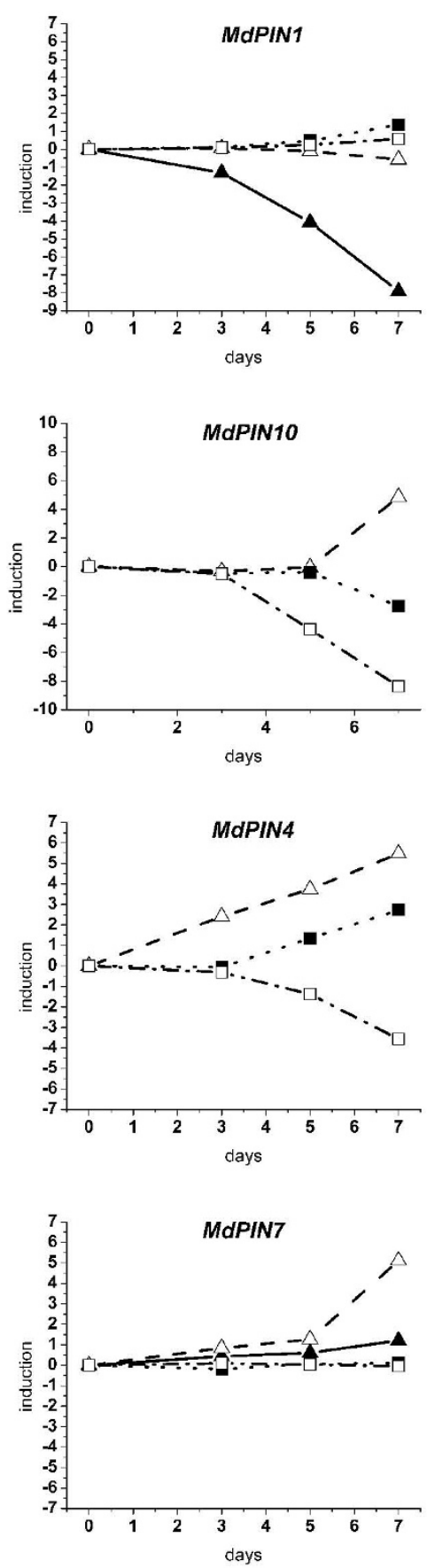
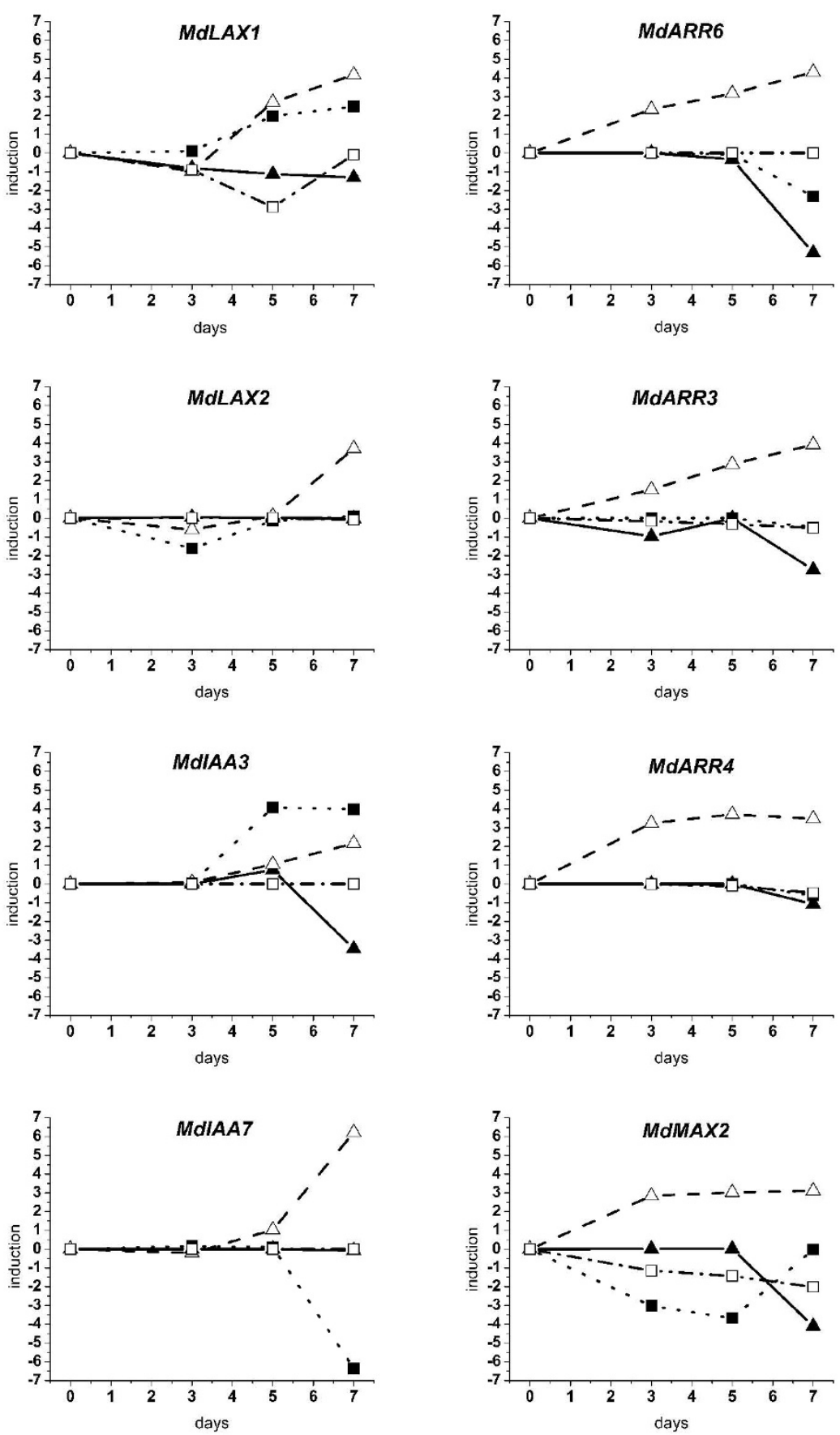

\section{Figure 4}

Expression study during abscission induction. Expression analysis in seed (solid triangle, continuous line), cortex (open triangle, dashed line), peduncle (solid square, dotted line) and AZ (open square, dashed-dotted line) performed by RT-PCR during abscission induction from 15 to 22 days APF. Samples were collected after triggering abscission with BA I5 days APF (time 0 ) and 3, 5 and 7 days later. Results are presented as folds induction compared to the TO of the ratio between the expression level in the abscising fruitlets and in the persistent ones, corrected for the internal control (ubiquitin). 

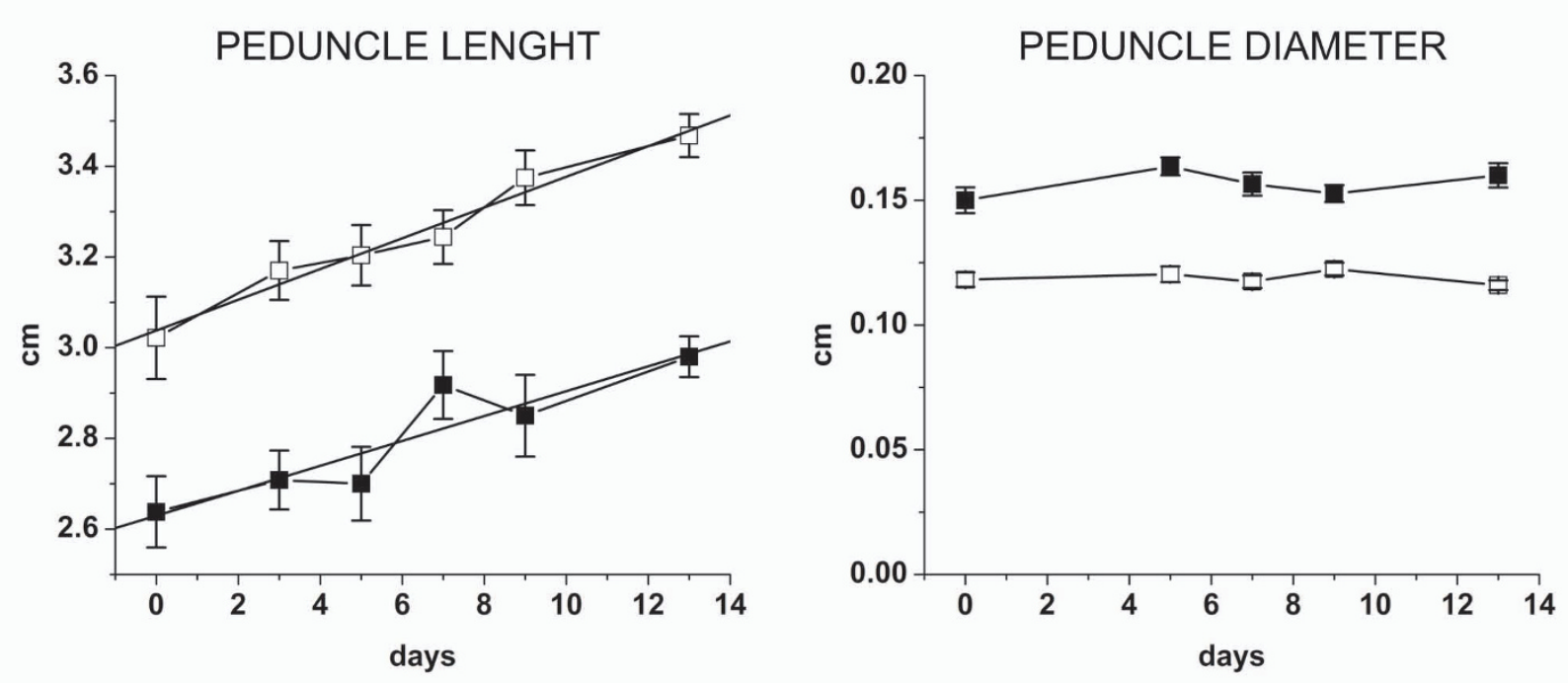

Figure 5

Peduncle growth. Peduncle length and diameter of the abscising fruitlets (open squares) and persistent fruitlets (solid squares) during abscission induction from I 5 to 29 days APF. Samples were collected 3, 5, 7, 9 and I 3 days after triggering abscission with BA at T0.

this phenomenon occurs in fruit exclusively at early development.

The cellular concentration of auxin is due to both transport rate and homeostasis, but in the wood forming tissues, the latter is largely predominant on synthesis, catabolism and conjugation due to the scarce capacity of the cells [64]. The peduncle and the AZ are mainly made up of this type of cells. Different patterns were found in transcripts accumulation: MdPIN10 decreased in peduncles and in the $\mathrm{AZ}$, whereas MdPIN4 increased in peduncle and decreased in $\mathrm{AZ}$, indicating a different nature of the tissues. We may hypothesize that during abscission induction the decrease in auxin flow coming from the seeds determines a change in the peduncle both in terms of auxin level, as assessed by the MdIAA7 transcript accumulation and in terms of PAT, because peduncle is the fruitlet organ in which MdPIN4 and MdPIN10 are mostly expressed and that the diverse PIN mutants display partially different phenotypes (as previously discussed). The vertical flux may be hampered due to an increase in the apolar distributed efflux carriers. In this scheme, the auxin flow through the $\mathrm{AZ}$ will progressively decrease, leading to AZ activation. Nevertheless, auxin at this stage may play a pivotal role in tissue differentiation leading to wood formation [68], as demonstrated by the isolation of auxin related clones putatively involved in the process $[69,70]$. In this case, the auxin flow may be directed, according to the signal flow canalization hypothesis [71], through a lateral transport mediated by specifically localized AECs such as MdPIN4. The difference in development between
$\mathrm{AF}$ and NAF is further confirmed by the higher level of MdLAX1 transcripts and by the reduced diameter of the lateral fruitlet peduncle. In agreement to what was observed for the hypocotyls during de-etiolation, the differential expression may also be related to a higher elongation rate. Nevertheless, despite the fact that $\mathrm{AF}$ peduncles are longer than NAF, there was no difference in the growth rate, thus indicating that the differential expression is unrelated to cell elongation but mainly related to tissue formation. Concerning $\mathrm{AZ}$, the transient decrease in MdLAX1 and the continuous decrease in MdPIN10 and MdPIN4 transcripts may indicate a redistribution of auxin.

\section{Abscission induction and dominance}

Abscission in apple is proposed to be due to competition between auxin flows coming from the different fruitlets in a dominance-like fashion [37]. The data herein presented indicate that during abscission induction there is a clear decrease in PAT-related transcripts in the seed, the key element in fruitlet dominance. It is then likely that the drop in auxin export capacity of AF leads to a weak auxin flow which cannot compete with the strong flux from the central fruitlet. As previously discussed, dominance is related to the capacity of the apex to attract cytokinins, which are positive regulators of type A ARR expression. Indeed, a decrease in MdARR6 and MdARR3 transcripts was observed in seeds during abscission induction, thus indicating a shortage in cytokinin. Nevertheless, the low level of cytokinin is likely due to a low biosynthetic rate rather than to a reduced import. It has been shown that there are 


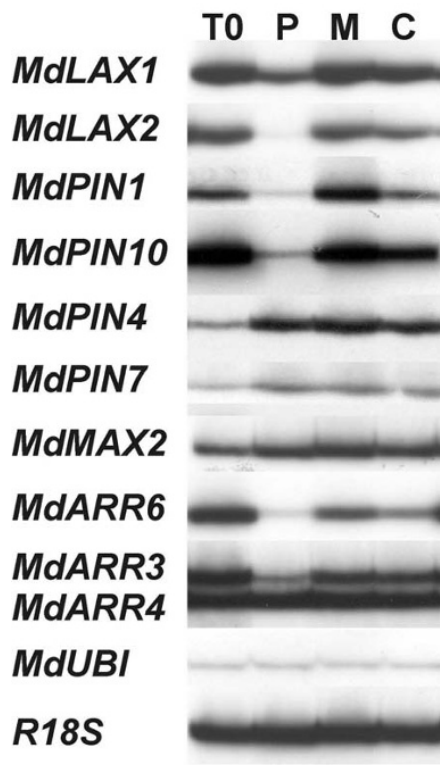

Figure 6

Ethylene effect on transcript accumulation. Expression analysis in peduncle of fruitlet clusters after 24 hours of propylene treatment $(\mathrm{P})$ or I-MCP (M) application. The control (C) represents untreated fruitlets after 12 hours from the beginning of the experiment (TO).

several IPT genes expressed at specific stages of seed development [72] and there is a specific developmental window during seed formation in which a large increase in seed cytokinin is observed in cereals and beans [73-76]. At this stage, cytokinins are believed to strengthen sink activity and to induce endosperm proliferation. Furthermore, the chalazal endosperm is thought to be involved in importing assimilates into the developing seeds [77]. Since cytokinins in seed are not exported, it is likely that they play a role as local mediators rather than systemic signals $[78,79]$. Considering MAX2, an additional element involved in apical dominance, its expression pattern in the different tissues is opposite to that of $M d L A X 2 / 3$, MdARR6 and MDPIN10, especially in seedlings. This divergence may indicate some common regulatory mechanisms in terms of transcription. Nevertheless, such relation is lacking in the tissues undergoing abscission, indicating that MdMAX2 may not play an important function in PIN regulation as reported in other systems but instead act in other processes such as senescence [80,81].

\section{Conclusion}

It appears that the expression level of genes related to auxin and the PAT elements are tightly correlated to abscission induction driven by dominance in apple. It is feasible that the strong auxin flow characterizing the central fruitlet dominates the weak ones [41]. Nevertheless, it is not clear what is the cue determining the fall in the seed PAT that triggers abscission. The best candidate is development, which is also affected by carbohydrate availability [82]. The developmental stage acts through the same auxin flow (small seeds produce less auxin and cytokinins) and with the likely involvement of ethylene. Indeed, ethylene has already been proven to affect auxin transport [83]. In this study, ethylene was also clearly shown to repress transcript accumulation of MdLAX1, MdLAX2, MdPIN1, MdPIN10, MdARR6 and MdARR3, indicating that the increase in its evolution at this stage may modulate seed development, leading to a reduced auxin export and the induction of abscission.

\section{Methods \\ Plant material}

The experiments were performed on Malus $\times$ domestica. Eight-year old apple trees (cv Golden Delicious/M9) were grown interspaced by pollinator trees (cv Stark Red). In order to investigate the expression profile of the identified clones in different tissues and in different physiological conditions, seed and cortex from ripe fruits at harvest, flowers at full bloom and un-pollinated senescing flowers, shoot, leaf and senescing leaf and seed, peduncle and cortex of fruitlets at 7 days after petal fall (APF) were collected. Furthermore, since seedlings are the usual system to study elements involved in PAT, seeds were sown in half MS media in the dark. Five days after germination, seedlings were either left for a further 4 days in the dark or moved to light. Root, cotyledon and hypocotyl were collected from seedlings at 5 days after germination and after 4 days of de-etiolation or darkness.

Fruitlets differing in the abscission potential were obtained as previously described with some minor modifications [39]. Abscising fruitlets (AF) were obtained from lateral fruitlets of clusters borne on trees sprayed with benzyladenine (BA) at $200 \mu \mathrm{g} \cdot \mathrm{L}^{-1}$ when the average fruit diameter was around $10 \mathrm{~mm}$ (15 days APF). The nonabscising fruitlets (NAF) were comprised of central fruitlets of clusters in which all the laterals had been removed 7 days APF. Seed, cortex, peduncle and abscission zone (AZ) were collected from NAF and AF at 0, 3, 5 and 7 days after the BA treatment of the AF population. The northern blot analysis (Additional file 10) was performed as previously described with the MdACO1 probe [40,84]. Results confirmed the validity of the populations obtained because the increase in MdACO1 transcript amount showed to be a reliable abscission marker [38,40,84]. Peduncle length and diameter of NAF and AF were measured with a calibre at 0,3, 5, 7, 9 and 11 days after BA treatment. Statistical analysis (T-test) was performed with the excel package. The equation and the regression coefficient were also calculated. 
Table 2: List of degenerate primers utilized in the isolation of genes

\begin{tabular}{|c|c|c|c|c|c|}
\hline Clone & & Primers & & $\mathbf{L}$ & Tm \\
\hline & & forward & reverse & bp & ${ }^{\circ} \mathrm{C}$ \\
\hline \multirow[t]{2}{*}{ LAX } & $S$ & 5'-AACCAYGTYATHCAGTGGTT-3' & 5'-GGRATGAYRTARACDGTGAA-3' & 840 & 58 \\
\hline & M & NHVIQWF & SFTVYIIP & & \\
\hline \multirow[t]{2}{*}{$\mathrm{PIN}$} & $S$ & 5'-CARWGYATHTGGTAYAC-3' & 5'-GCAYYARCATYCCAAADAT-3' & 1400 & 57 \\
\hline & M & QCIIWY & VIFGMLM & & \\
\hline ARR type & $S$ & 5'-CATGTTYTNGCBGTTGATG-3' & 5'-CATNCCRGGCATDSAGTARTC-3' & 200 & 60 \\
\hline A & $M$ & HVLAVDDS & TDYSMPGM & & \\
\hline
\end{tabular}

Degenerate primers used for the isolation of partial clones of LAX, PIN, and ARR type A identified in this study. S indicates the oligonucleotide sequence while $M$ the conserved protein sequence chosen to design the primers. The amplification length of the product (L) expressed in bp and the annealing temperature are also reported.

\section{Hormone treatments}

Auxin treatment was performed only on the peduncle, because the peduncle is the tissue most respondent to auxin [61]. IAA was dissolved in a constant amount of alcohol at a final concentration of $0.1,1,5$ and $10 \mathrm{mM}$. The mock control consisted of peduncle treated with water and the quantity of alcohol used for auxin solubilisation. The entire experiment was performed in the dark. The central part of the peduncle $(1.5 \mathrm{~cm})$ was isolated from lateral fruitlets at 15 days after petal fall (DAPF) (T0), immersed in the auxin solution and a vacuum applied for $10 \mathrm{~min}$, and then was left for an additional 120 min under normal conditions and sampled. Entire apple fruitlet clusters at 15 DAPF were treated with propylene $\left(1000 \mu \mathrm{L} \cdot \mathrm{L}^{-1}\right)$ or 1 -MCP $\left(1 \mu \mathrm{L} \cdot \mathrm{L}^{-1}\right)$ or left untreated (control) as described in [61]. Tissue was collected at the beginning of the experiment (T0) and after 24 hours for molecular analysis.

\section{Clone isolation and expression analysis}

Total RNA extraction and single strand cDNA synthesis were performed as previously reported [85,39]. The isolation of the partial clones was performed with degenerate primers designed on conserved areas of the ORFs (Table 2) [86]. The reaction was performed in $1 \times$ PCR Buffer (Amersham Pharmacia), $0.25 \mathrm{mM}$ dNTPs, $1 \mu \mathrm{M}$ primer forward, $1 \mu \mathrm{M}$ primer reverse, and $0.05 \mathrm{U} / \mu \mathrm{l}$ of Taq (Amersham Pharmacia). The PCR profile was as follows: 5 min hold at $95^{\circ} \mathrm{C}$ and 40 cycles composed by $60 \mathrm{~s}$ at $94^{\circ} \mathrm{C}, 60 \mathrm{~s}$ at the primer annealing temperature (Tm) and $90 \mathrm{~s}$ of extension at $72^{\circ} \mathrm{C}$. Tm was as reported in Table 1. The cycles were followed by a final step of $7 \mathrm{~min}$ at $72^{\circ} \mathrm{C}$.

The 3'UTR of the clones was subsequently obtained with specific primers (Table 3) as previously described [40]. Briefly the 3'RACE was performed with a gene specific for- ward primer and the anchored oligo $\mathrm{dT}$ as the reverse primer. Annealing temperature was as reported in Table 2.

The genomic sequences of MdPIN1 and MdPIN10 were obtained from the amplification of DNA extracted from leaves of Golden Delicious apples with the Qiagen DNA easy according to manufacturer instructions. The template (100 ng) was amplified in $1 \times$ PCR buffer (Amersham), $0.03 \mathrm{U} \mu \mathrm{L}^{-1} \mathrm{Taq}$ (Amersham Pharmacia), $0.3 \mu \mathrm{M}$ of primer forward (5'-CGGGATCCATTGTCTCCA-3') and $0.3 \mu \mathrm{M}$ of primer reverse (5'-GGAAACTCCATTGCAGCT-3'). The amplification profile was as follows: an initial denaturation for $5 \mathrm{~min}$ at $95^{\circ} \mathrm{C}, 40$ cycles composed by $60 \mathrm{~s}$ at $94^{\circ} \mathrm{C}, 90 \mathrm{~s}$ at $62^{\circ} \mathrm{C}$ and $90 \mathrm{~s}$ at $72^{\circ} \mathrm{C}$, and a final step of 7 $\min$ at $72^{\circ} \mathrm{C}$

Amplification fragments were electrophoresed in agarose gel, purified and cloned into pGEM-T Easy vector

Table 3: List of primers utilized in the isolation of the 3' part of the genes isolated in this study

\begin{tabular}{ccc}
\hline Clone & Primers & Tm \\
\hline LAXI & 5'-TTTCTCTCTCCTCCCCAAGAAC-3' & 68 \\
\hline LAX2/3 & 5'-CTTTGGATCTGTCATCCAACTTATAG-3' & 71 \\
\hline PINI/10 & 5'-GGCCTCACTTGGTCTCTAGTCTCA-3' & 70 \\
\hline PIN4/7 & 5'-GTATTCGAGCCTCATTGGTCTCATC-3' & 70 \\
\hline ARR3/4 & 5'-CGAGGGATGTCGGAGTGGAAGAG-3' & 69 \\
\hline ARR6 & 5'-CAGCGGGACGAGAGCTCTGGAG-3' & 69
\end{tabular}

Specific primers used in the 3' RACE for the isolation of the 3' part of LAX, PIN, and ARR type A. The annealing temperature is also reported. 
(Promega). Positive clones were grown and plasmids were isolated with the Miniprep Kit (Qiagen) and sequenced using the ABIPRISM BigDye Terminator v3.1 kit (Applied Biosystems).

Contigs were assembled by the SeqMan software (DNAstar package) while sequence comparisons were performed using BlastX and BlastN algorithms (NCBI, National Centre for Biotechnology Information). Sequence alignment between the deduced proteins of the clones identified here and those from LAX and PIN members of Arabidopsis thaliana (AtAUX1，NP_565882; AtLAX1，NP_195744, NP_974719; AtLAX2, NP_179701; AtLAX3, NP_177892; AtPIN1，NP_177500，AF089085; AtPIN2，NP_568848; AtPIN3, NP_177250; AtPIN4, NP_565261, NP_849923; AtPIN5, NP_197157; AtPIN6, NP_177836; AtPIN7, NP_564189， NP_849700， NP_001077584; AtPIN8, NP_197014), Medicago truncatula (MtLAX1, Q9FEL8; MtLAX2, Q9FEL7; MtLAX3, Q9FEL6; MtLAX4，Q8L884; MtLAX5, Q8L883; MtPIN1, AAM55297; MtPIN2, AAM55298; MtPIN3, AAM55299; MtPIN4, AAM55300; MtPIN5, AAM55301; MtPIN6, AAT48627; MtPIN7, AAT48628; MtPIN8, DAA05219; MtPIN9, AAT48629; MtPIN10, AAT48630) and Populus tremula $\times$ Populus tremuloides (PttLAX1， AAF21982; PttLAX2， AAG17171; PttLAX3, AAK58522; PttPIN1， AAG17172; PttPIN2, AAM54033; PttPIN3, AAM54034) were performed with the aid of the Clustal $\mathrm{W}$ algorithm using default settings (MegAlign software, DNAstar package).

Expression analysis of the clones was performed by the semi-quantitative PCR implemented with ${ }^{33} \mathrm{P}$ labeled primers as previously described [40]. Specific conditions of this experiment are reported in Table 3. Data concerning the abscission experiment are expressed as fold induction of the ratio between the level of expression in $\mathrm{AF}$ and NAF populations, corrected for the transcript amount of the constitutive gene (MdUBI). Data referring to auxin application are presented as fold induction after correction for the level of the constitutive gene (MdUBI). Changes of at least 0.5 fold magnitudes are considered significant.

\section{Abbreviations}

AF: Abscising Fruitlet; ARR: Arabidopsis Response Regulator; At: Arabidopsis thaliana; Aux/IAA: Aux/IAA; AUX: AUXin; AZ: abscission zone; DAPF: days after petal fall; dad: Decreased Apical Dominance; GFP: green fluorescent protein; IAA: indol acetic acid; LAX: Like AUX; MAX: Maximum Axillary; Md: Malus $\times$ domestica; Mt: Medicago truncatula; NAF: Non Abscising Fruitlet; PAT: Polar Auxin Transport; PIN: PIN FORMED; rms: ramosus; T0: time 0; UBI: UBIquitin.

\section{Authors' contributions}

VDC conceived and designed the experimental study, performed the experiments, and wrote the manuscript. RV gave intellectual guidance and financially supported the research. AR conceived and designed the experimental study, gave intellectual guidance, financially supported the research and wrote the manuscript. All authors read and approved the final manuscript.

\section{Additional material}

\section{Additional file 1}

Scheme of the PINs isolated in this study. The scheme illustrates the partial clones of PIN isolated in this study. Rectangles represent the CDS whereas the line indicates the UTR. The blank rectangle and the dotted line represent the missing sequence. The stop codon is reported in capital letter between the CDS and the 3' UTR. The string of four A, where present, indicates the polyA tail. The length of the parts is reported in base pairs (bp) at the bottom.

Click here for file

[http://www.biomedcentral.com/content/supplementary/14712229-9-139-S1.pdf]

\section{Additional file 2}

Scheme of the LAX isolated in this study. The scheme illustrates the partial clones of LAX isolated in this study. Rectangles represent the CDS whereas the lines indicate the UTR. The blank rectangle and the dotted line represent the missing sequence. The stop codon is reported in capital letter between the CDS and the 3' UTR. The string of four A, where present, indicates the polyA. The length of the parts is reported in base pairs (bp) at the bottom.

Click here for file

[http://www.biomedcentral.com/content/supplementary/14712229-9-139-S2.pdf]

\section{Additional file 3}

Identity values among the PIN isolated in this study with those of several species. Identity values among the protein sequences of PIN isolated in this study from Malus $\times$ domestica (Md) and those of Arabidopsis thaliana (At), Medicago truncatula $(M t)$, and Populus tremula $\times$ Populus tremuloides (Ptt). (MdPIN1_A, EF406255; MdPIN1_B, EF406256; MdPIN4, EF406257; MdPIN7_A, EF406258;

MdPIN7_B, EF406259; MdPIN10_A, EF406260; MdPIN10_B, EF406261; AtPIN1, NP_177500; AF089085; AtPIN2, NP_568848; AtPIN3, NP 177250; AtPIN4, NP 565261, NP 849923; AtPIN5, NP_197157; AtPIN6, NP_177836; AtPIN7, NP_564189,

NP_849700,NP_001077584; AtPIN8, NP_197014; MtPIN1, AAM55297; MtPIN2, AAM55298; MtPIN3, AAM55299; MtPIN4, AAM55300; MtPIN5, AAM55301; MtPIN6, AAT48627; MtPIN7, AAT48628; MtPIN8, DAA05219; MtPIN9, AAT48629; MtPIN10, AAT48630; PttPIN1, AAG17172; PttPIN2, AAM54033; PttPIN3, AAM54034).

Click here for file

[http://www.biomedcentral.com/content/supplementary/14712229-9-139-S3.jpeg] 


\section{Additional file 4}

Identity values of the intronic regions. The values are the identity percentages of the intronic nucleotide sequences of MdPIN1 (EF406268), MdPIN10_A (EF406269) and MdPIN10_B (EF406270) obtained with the clastalW alignment. Length is represented on the left and expressed as base pairs (bp).

Click here for file

[http://www.biomedcentral.com/content/supplementary/14712229-9-139-S4.tiff]

\section{Additional file 5}

Identity values among the LAX isolated in this study and those of several species. Identity values among the protein sequencesLAX isolated in this study from Malus $\times$ domestica (Md) with those of Arabidopsis thaliana (At), Medicago truncatula (Mt), and Populus tremula $\times$ Populus tremuloides (Ptt). (MdLAX1, EF406263; MdLAX2, EF406264; MdLAX3, EF406262; AtAUX1, NP_565882; AtLAX1, NP_195744, NP 974719; AtLAX2, NP_179701; AtLAX3, NP_177892; MtLAX1, Q9FEL8; MtLAX2, Q9FEL7; MtLAX3, Q9FEL6; MtLAX4, Q8L884; MtLAX5, Q8L883; PttLAX1, AAF21982; PttLAX2, AAG17171; PttLAX3, AAK58522).

Click here for file

[http://www.biomedcentral.com/content/supplementary/14712229-9-139-S5.jpeg]

\section{Additional file 6}

Expression analysis with degenerative primers. The expression analysis was performed with PIN degenerate primers on cDNA of peduncle. Click here for file

[http://www.biomedcentral.com/content/supplementary/14712229-9-139-S6.tiff]

\section{Additional file 7}

Expression analysis of PINs following auxin application. The expression analysis of PIN was preformed on CDNA from peduncle tissue treated with auxin at different concentration: $0.1,1,5,10 \mathrm{mM}$ and the mock control (M) for 90 min. Expression data are corrected for the constitutive gene and presented as fold induction compared to the beginning of the experiment (TO).

Click here for file

[http://www.biomedcentral.com/content/supplementary/14712229-9-139-S7.jpeg]

\section{Additional file 8}

PIN Phylogenetic tree. Phylogenetic tree of the PINs isolated in this study from MalusXdomestica (Md) and those of Arabidopsis thaliana (At), Medicago truncatula $(\mathrm{Mt})$, Oryza sativa $(\mathrm{Os})$ cultivar indica (ind) and japonica (jap), Populus tremula $\times$ Populus tremuloides (Ptt), Populus balsamifera subsp. trichocarpa (Ptric), Physcomitrella patens subsp patens $(P p)$ and several varieties of Vitis vinifera $(V v)$ from different varieties. Bootstrap values are indicated. Var means transcript variation. The accession number is reported at the end of the sequence name.

Click here for file

[http://www.biomedcentral.com/content/supplementary/14712229-9-139-S8.pdf]

\section{Additional file 9}

LAX phylogenetic tree. Phylogenetic tree of the LAX isolated in this study from MalusXdomestica (Md) and those of Arabidopsis thaliana (At), Medicago truncatula $(\mathrm{Mt})$, Oryza sativa (Os)cultivar indica (ind) and japonica (jap), Populus tremula $\times$ Populus tremuloides (Ptt), Populus balsamifera subsp. trichocarpa (Ptric), Physcomitrella patens subsp patens $(P p)$ and several varieties of Vitis vinifera $(V v)$ from different varieties. Bootstrap values are indicated. The accession number is reported after the sequence. The accession number is reported at the end of the sequence name.

Click here for file

[http://www.biomedcentral.com/content/supplementary/14712229-9-139-S9.pdf]

\section{Additional file 10}

MdACO1 expression analysis during abscission. The expression analysis was performed by northern blot on the sample utilized in this study: AF (abscising fruitlets) and NAF (non-abscising fruitlets) at 0, 35 and 7 days during abscission induction. The control is represented by $18 \mathrm{~S}$ Click here for file [http://www.biomedcentral.com/content/supplementary/14712229-9-139-S10.pdf]

\section{Acknowledgements}

We are grateful to Giulio Galla for technical assistance in the expression analysis of the PIN genes

\section{References}

I. Taylor JE, Whitelaw CA: Signals in abscission. New Phyto 200I, | 5 |:323-339.

2. Abeles FB, Rubinstein B: Regulation of ethylene evolution and leaf abscission by auxin. Plant Phys 1964, 39:963-969.

3. Rubenstein B, Leopold AC: Analysis of the auxin control of bean leaf abscission. Plant Phys 1963, 38:262-267.

4. Sexton R, Roberts JA: Cell biology of abscission. Annu Rev in Plant Phys 1982, 33:133-162.

5. Bleecker AB, Patterson SE: Last exit: senescence, abscission, and meristem arrest in Arabidopsis. The Plant Cell 1997, 9:1169-1179.

6. Patterson SE, Bleecker AB: Ethylene-dependent and independent processes associated with floral organ abscission in Arabidopsis. Plant Phys 2004, 134:194-203.

7. Cai S, C Lashbrook C: Stamen abscission zone transcriptome profiling reveals new candidates for abscission control: enhanced retention of floral organs in transgenic plants overexpressing Arabidopsis ZINC FINGER PROTEIN2. Plant Phys 2008, 146: I305-I32I.

8. Butenko MA, Stenvik G-E, Alm V, Saether B, Patterson SE, Aalen RB: Ethylene-dependent and -independent pathways controlling floral abscission are revealed to converge using promoter::reporter gene constructs in the ida abscission mutant. J of Exp Bot 2006, 57:3627-3637.

9. Sabatini S, Beis D, Wolkenfelt H, Murfett J, Guilfoyle T, Malamy J, Benfey P, Leyser O, Bechtold N, Weisbeek P, Scheres B: An auxindependent distal organizer of pattern and polarity in the Arabidopsis root. Cell 1999, 99:463-472.

10. Benkova E, Michniewicz M, Sauer M, Teichmann T, Seifertova D, Jurgens G, Friml J: Local, efflux-dependent auxin gradients as a common module for plant organ formation. Cell 2003, I 1 5:59|-602.

II. Mattsson J, Ckurshumova W, Berleth T: Auxin signaling in Arabidopsis leaf vascular development. Plant Phys 2003, | 3 1: | 327-1339. 
12. Woodward AW, Bartel B: Auxin: regulation, action, and interaction. Ann of Bot 2005, 95:707-735.

13. Kepinski S, Leyser O: The Arabidopsis F-box protein TIRI is an auxin receptor. Nature 2005, 435:446-45।.

14. Dharmasiri N, Dharmasiri S, Estelle M: The F-box protein TIRI is an auxin receptor. Nature 2005, 435:44I-445

15. Tiwari SB, Wang XJ, Hagen G, Guilfoyle T]: AUX/IAA proteins are active repressors, and their stability and activity are modulated by auxin. The Plant Cell 200I, I 3:2809-2822.

16. Abebie B, Lers A, Philosoph-Hadas S, Goren R, Riov J, Meir S: Differential effects of NAA and 2,4-D in reducing floret abscission in Cestrum (Cestrum elegans) cut flowers are associated with their differential activation of Aux/IAA homologous genes. Ann of Bot 2007: I-II.

17. Abel S, Oeller PW, Theologis A: Early auxin induced genes encode short-lived nuclear proteins. Proceedings of the Nat Acad of Sci 1994, 91 : 326-330.

18. Abel S, Nguyen MD, Theologis A: The PS-IAA4/5-like family of early auxin-inducible mRNAs in Arabidopsis thaliana. J of Mol Biol | 995, 25 I:533-549.

19. Abel S, Theologis A: Early genes and auxin action. Plant Phys 1996, III:9-17.

20. Friml J: Auxin transport--shaping the plant. Curr Opin in Plant Biol 2003, 6:7-12.

21. Kramer EM, Bennett MJ: Auxin transport: a field in flux. Trends in Plant Sci 2006, II:382-386.

22. Bennett MJ, Marchant A, Green HG, May ST, Ward SP, Millner PA Walker AR, Schulz B, Feldmann KA: Arabidopsis AUXI gene: A permease-like regulator of root gravitropism. Science 1996, 273:948-950.

23. Yang J, Peng S, Visperas RM, Sanico AL, Zhu Q, Gu S: Grain filling pattern and cytokinin content in the grains and roots of rice plants. Plant Growth Reg 2000, 30:26I-270.

24. Santelia D, Vincenzetti V, Azzarello E, Bovet L, Fukao Y, Duchtig P, Mancuso S, Martinoia E, Geisler M: MDR-like ABC transporter AtPGP4 is involved in auxin-mediated lateral root and root hair development. FEBS Letters 2005, 579:5399-5406.

25. Terasaka K, Blakeslee J], Titapiwatanakun B, Peer WA, Bandyopadhyay A, Makam SN, Lee OR, Richards EL, Murphy AS, Sato F, Yazaki K: PGP4, an ATP binding cassette P-glycoprotein, catalyzes auxin transport in Arabidopsis thaliana roots. The Plant Cell 2005, I 7:2922-2939.

26. Chen RJ, Hilson P, Sedbrook J, Rosen E, Caspar T, Masson PH: The Arabidopsis thaliana AGRAVITROPIC I gene encodes a component of the polar-auxin-transport efflux carrier. Proceedings of the Nat Acad of Sci USA 1998, 95:15। I 2-15I I7.

27. Luschnig C, Gaxiola RA, Grisafi P, Fink GR: EIRI, a root-specific protein involved in auxin transport, is required for gravitropism in Arabidopsis thaliana. Genes Devel 1998, I 2:2 175-2 I87.

28. Petrasek J, Mravec J, Bouchard R, Blakeslee JJ, Abas M, Seifertova D, Wisniewska J, Tadele Z, Kubes M, Covanova M, Dhonukshe P, Skupa P, Benkova E, Perry L, Krecek P, Lee OR, Fink GR, Geisler M, Murphy AS, Luschnig C, Zazimalova E, Friml J: PIN proteins perform a rate-limiting function in cellular auxin efflux. Science 2006 , 3। 2:9|4-9|8.

29. Geisler M, Blakeslee J], Bouchard R, Lee OR, Vincenzetti V, Bandyopadhyay A, Titapiwatanakun B, Peer WA, Bailly A, Richards EL, Ejendal KF, Smith AP, Baroux C, Grossniklaus U, Muller A, Hrycyna CA Dudler R, Murphy AS, Martinoia E: Cellular efflux of auxin catalyzed by the Arabidopsis MDR/PGP transporter AtPGPI. The Plant Jour 2005, 44: 179-194.

30. Bouchard R, Bailly A, Blakeslee IJ, Oehring S, Vincenzetti V, Lee OR, Paponov I, Palme K, Mancuso S, Murphy AS, Schulz B, Geisler M: Immunophilin-like TWISTED DWARFI modulates auxin efflux activities of Arabidopsis P-glycoproteins. I of Biol Chem 2006, 28I:30603-306/2

31. Blakeslee IJ, Bandyopadhyay A, Lee OR, Mravec J Titapiwatanakun B, Sauer M, Makam SN, Cheng Y, Bouchard R, Adamec J, Geisler M, Nagashima A, Sakai T, Martinoia E, Friml J, Peer WA, Murphy AS Interactions among PIN-FORMED and P-glycoprotein auxin transporters in Arabidopsis. The Plant Cell 2007, 19:131-147.

32. Zažímalová $E$, Køeèek $P$, Skùpa $P$, Hoyerová $K$, Petrášek J: Polar transport of the plant hormone auxin - the role of PINFORMED (PIN) proteins. Cellular and Mol Life Sci (CMLS) 2007, 64:1621-1637.
33. Friml J, Vieten A, Sauer M, Weijers D, Schwarz H, Hamann T, Offringa $R$, Jurgens $G$ : Efflux-dependent auxin gradients establish the apical-basal axis of Arabidopsis. Nature 2003, 426: I47-I 53.

34. Blilou I, Xu J, Wildwater M, Willemsen V, Paponov I, Friml J, Heidstra R, Aida M, Palme K, Scheres B: The PIN auxin efflux facilitator network controls growth and patterning in Arabidopsis roots. Nature 2005, 433:39-44.

35. Whitelaw CA, Lyssenko NN, Chen L, Zhou D, Mattoo AK, Tucker $M L$ : Delayed abscission and shorter internodes correlate with a reduction in the ethylene receptor LeETRI transcript in transgenic tomato. Plant Phys 2002, 1 28:978-987.

36. Klee H]: Ethylene signal transduction. Moving beyond Arabidopsis. Plant Phys 2004, 135:660-667.

37. Bangerth $F$ : Abscission and thinning of young fruit and their regulation by plant hormones and bioregulators. Plant Growth Reg 2000, 31:43-59.

38. Dal Cin V, Danesin M, Boschetti A, Dorigoni A, Ramina A: Ethylene biosynthesis and perception in apple fruitlet abscission (Malus domestica L. Borkh). J of Exp Bot 2005, 56:2995-3005

39. Dal Cin V, Galla G, Ramina A: MdACO EXPRESSION DURING ABSCISSION The use of ${ }^{33} \mathrm{P}$ labeled primers in transcript quantitation. Mol Biotech 2007, 36:9-13.

40. Dal Cin V, Boschetti A, Dorigoni A, Ramina A: Benzylaminopurine application on two different apple cultivars (Malus domestica L. Borkh) displays new and unexpected fruitlet abscission features. Ann of Bot 2007 99:1195-1202.

4I. Bangerth F, Chun-Jan L, Gruber J: Mutual interaction of auxin and cytokinins in regulating correlative dominance. Plant Growth Reg 2000, 32:205-217.

42. Sachs T: Pattern Formation in Plant Tissues Cambridge Univ. Press, Cambridge, U.K; 1991:83-93.

43. Leyser O: Regulation of shoot branching by auxin. Trends in Plant Sci 2003, 8:54I-545

44. Leyser O: The fall and rise of apical dominance. Curr Opin in Genet Devel 2005, I 5:468-47I.

45. McSteen P, Leyser O: Shoot Branching. Annu Rev of Plant Biol 2005, 56:353-374.

46. Cline MG: Apical dominance. Bot Rev 199I, 57:3।8-358.

47. Werner T, Motyka V, Strnad M, Schmülling T: Regulation of plant growth by cytokinin. Proceedings of the Natl Acad of Sci, USA 200I, 98: 10487-10492.

48. Werner T, Motyka V, Laucou V, Smets R, Van Onckelen H, Schmulling $\mathrm{T}$ : Cytokinin-deficient transgenic Arabidopsis plants show multiple developmental alterations indicating opposite functions of cytokinins in the regulation of shoot and root meristems activity. The Plant Cell 2003, 15:2532-2550.

49. Tanaka M, Takei K, Kojima M, Sakakibara H, Mori : Auxin controls local cytokinin biosynthesis in the nodal stem in apical dominance. The Plant Jour 2006, 45:1028-1036.

50. Hutchinson CE, Kieber J]: Cytokinin signaling in Arabidopsis. The Plant Cell 2002:S47-S59.

5I. D'Agostino IB, Derue're J, Kieber JJ: Characterization of the response of the Arabidopsis response regulator gene family to cytokinin. Plant Phys 2000, 124:1706-1717.

52. Gomez-Roldan V, Fermas S, Brewer PB, Puech-Pagès V, Dun EA, Pillot JP, Letisse F, Matusova R, Danoun S, Portais JC, Bouwmeester H, Bécard G, Beveridge CA, Rameau C, Rochange SF: Strigolactone inhibition of shoot branching. Nature 2008, 455: 189-194.

53. Beveridge CA, Symons GM, Turnbull CGN: Auxin inhibition of decapitation-induced branching is dependent on graft-transmissible signals regulated by genes rmsI and rms2. Plant Phys 2000, 123:689-697.

54. Napoli C: Highly branched phenotype of the petunia dadI-I mutant is reversed by grafting. Plant Phys 1996, I I I:27-37.

55. Stirnberg P, Sande $K$ van de, Leyser HM: MAXI and MAX2 control shoot lateral branching in Arabidopsis. Devel 2002, |29:||3|-||4|.

56. Booker J, Sieberer T, Wright W, Williamson L, Willett B, Stirnberg S, Turnbull C, Srinivasan P, Goddard P, Leyser O: The MAX I gene of Arabidopsis encodes a putative cytochrome P450 that acts downstream of MAX3 and MAX4 in the synthesis of a novel branch-inhibiting hormone. Devel Cell 2005, 8:443-449.

57. Stirnberg P, Furner IJ, Leyser HMO: MAX2 participates in an SCF complex which acts locally at the node to suppress shoot branching. The Plant Jour 2007, 50:80-94. 
58. Dal Cin V, Barbaro E, Danesin M, Murayama $H$, Velasco R, Ramina A Fruitlet abscission: A cDNA-AFLP approach to study genes differentially expressed during shedding of immature fruits reveals the involvement of a putative auxin hydrogen symporter in apple (Malus domestica L. Borkh). Gene 2009, 442:26-36.

59. Schnabel EL, Frugoli J: The PIN and LAX families of auxin transport genes in Medicago truncatula. Mol Genet Genomics 2004, 272:420-432.

60. Chawla R, DeMason DA: Molecolar expression of PsPINI, a putative auxin efflux carrier gene from pea (Pisum sativum L.). Plant Growth Reg 2004, 44: I-I 4.

6I. Dal Cin V, Galla G, Boschetti A, Dorigoni A, Velasco R, Ramina A Ethylene involvement in auxin transport during apple fruitlet abscission. (Malus $\mathbf{x}$ domestica $\mathbf{L}$. Borkh). In Advances in Plant Ethylene Research: Proceedings of the 7th Symposium on the Plant Hormone Ethylene Edited by: Ramina A, Perata P, Chang C, Giovannoni J, Klee H. New York: Springer-Verlag; 2007:89-93.

62. Moyle R, Schrader J, Stenberg A, Olsson O, Saxena S, Sandberg G, Bhalerao RP: Environmental and auxin regulation of wood formation involves members of the Aux/lAA gene family in hybrid aspen. The Plant Jour 2002, 31:675-685.

63. Wang $\mathrm{H}$, Jones $B$, Li Z Frasse $P$, Delalande C, Regad F Chaabouni S, Latche A, Pech JC, Bouzayen M: The tomato Aux/IAA transcription factor IAA9 is involved in fruit development and leaf morphogenesis. The Plant Cell 2005, 17:2676-2692.

64. Schrader J, Nilsson J, Mellerowicz E, Berglund A, Nilsson P, Hertzberg $M$, Sandberg G: A high-resolution transcript profile across the wood-forming meristem of poplar identifies potential regulators of cambial stem cell identity. The Plant Cell 2004, 16:2278-2292

65. Vieten A, Vanneste S, Wisniewska J, Benkova E, Benjamins R, Beeckman T, Luschnig C, Friml J: Functional redundancy of PIN proteins is accompanied by auxin-dependent crossregulation of PIN expression. Devel 2005, I32:452I-453I.

66. Hunter DA, Steele BC, Reid MS: Identification of genes associated with perianth senescence in Daffodil (Narcissus pseudonarcissus L. 'Dutch Master'). Plant Sci 2002, I63:13-2I.

67. Brenner WG, Romanov GA, Kollmer I, Burkle L, Schmulling T: Immediate-early and delayed cytokinin response genes of Arabidopsis thaliana identified by genome-wide expression profiling reveal novel cytokinin-sensitive processes and suggest cytokinin action through transcriptional cascades. The Plant Journal 2005, 44:3। 4-333.

68. Mattsson J, Sung ZR, Berleth T: Responses of plant vascular systems to auxin transport inhibition. Devel 1999, I 26:2979-299|.

69. Demura T, Tashiro G, Horiguchi G, Kishimoto N, Kubo M, Matsuoka N, Minami A, Nagata-Hiwatashi M, Nakamura K, Okamura Y, Sassa N, Suzuki S, Yazaki J, Kikuchi S, Fukuda H: Visualization by comprehensive microarray analysis of gene expression programs during transdifferentiation of mesophyll cells into xylem cells. Proceedings of the Nat Acad of Sci 2002, 99:15794-15799.

70. Paux E, Tamasloukht M, Ladouce N, Sivadon P, Grima-Pettenati ]: Identification of genes preferentially expressed during wood formation in Eucalyptus. Plant Mol Biol 2004, 55:263-280.

7I. Sachs T: The control of patterned differentiation of vascular tissues. Adv Botanical Research 198I, 9:15I-162.

72. Miyawaki K, Matsumoto-Kitano M, Kakimoto T: Expression of cytokinin biosynthetic isopentenyltransferase genes in Arabidopsis: tissue specificity and regulation by auxin, cytokinin, and nitrate. The Plant Jour 2004, 37:128-138.

73. Neil Emery RJ, Ma Q, Atkins CA: The forms and sources of cytokinins in developing white lupine seeds and fruits. Plant Phys 2000:1953-1604

74. Lorenzi R, Bennici A, Cionini PG, Alpi A, D'Amato F: Embryo-suspensor relations in Phaseolus coccineus: cytokinins during seed development. Planta 1978, 143:59-62.

75. Morris RO, Blevins DG, Dietrich JT, Durley RC, Gelvin SB, Gray J, Hommes NG, Kaminek M, Mathews LI, Meilan R, Reinbott TM, Sayavedra-Soto L: Cytokinins in Plant Pathogenic Bacteria and Developing Cereal Grains. Australian J of Plant Phys 1993, 20:62I-637

76. Yang Y, Hammes UZ, Taylor CG, Schachtman DP, Nielsen E: Highaffinity auxin transport by the AUXI influx carrier protein. Curr Biol 2006, 16:1123-1127.
77. Berger F: Endosperm: the crossroad of seed development. Curr Opin in Plant Biol 2003, 6:42-50.

78. Letham DS, Williams MW: Regulators of cell division in plant tissues VUI. The cytokinins of the apple fruit. Physiologia Plantarum 1969, 22:925-936.

79. Faiss M, Zalubillová J, Strnad M, Schmülling T: Conditional transgenic expression of the ipt gene indicates a function for cytokinins in paracrine signaling in whole tobacco plants. The Plant Jour 2002, | 2:40|-4I5.

80. Bennett T, Sieberer T, Willett B, Booker J, Luschnig C, Leyser O: The Arabidopsis MAX pathway controls shoot branching by regulating auxin transport. Curr Bio 2006, 16:553-563.

8I. Woo HR, Chung KM, Park J-H, Oh SA, Ahn T, Hong SH, Jang SK, Nam HG: ORE9, an F-Box protein that regulates leaf senescence in Arabidopsis. The Plant Cell 200I, I3:1779-1790.

82. Zhou C, Lakso AN, Robinson TL, Gan S: Isolation and characterization of genes associated with shade-induced apple abscission. Mol Genet Genomics 2008, 280:83-92.

83. Negi S, Ivanchenko MG, Muday GK: Ethylene regulates lateral root formation and auxin transport in Arabidopsis thaliana. The Plant Jour 2008, 55: 175-187.

84. Dal Cin V, Rizzini FM, Botton A, Tonutti P: The ethylene biosynthetic and signal transduction pathways are differently affected by I-MCP in apple and peach fruit. Postharvest Biol and Tech 2006, 42:125-133.

85. Dal Cin V, Danesin M, Rizzini FM, Ramina A: RNA extraction from plant tissues: the use of calcium to precipitate contaminating pectic sugars. Mol Biotech 2005, 3 I: I I 3-I20.

86. Nguyen $\mathrm{P}, \mathrm{Dal} \mathrm{C}$ in $\mathrm{V}$ : The role of light on foliage colour development in coleus (Solenostemon scutellariodes (L.) Codd). Plant Phys and Biochem 2009, 47:934-945.
Publish with Bio Med Central and every scientist can read your work free of charge

"BioMed Central will be the most significant development for disseminating the results of biomedical research in our lifetime. "

Sir Paul Nurse, Cancer Research UK

Your research papers will be:

- available free of charge to the entire biomedical community

- peer reviewed and published immediately upon acceptance

- cited in PubMed and archived on PubMed Central

- yours - you keep the copyright
BiolMedcentral 